\title{
An investigation of a biomass hydrogel electrolyte naturally stabilising cathodes for zinc-ion batteries
}

Haobo Dong ${ }^{a}$, Jianwei $\mathrm{Li}^{a}$, Siyu Zhao ${ }^{a}$, Yiding Jiao ${ }^{a}$, Jintao Chen ${ }^{a}$, Yeshu Tan ${ }^{a}$, Dan J.L. Brett ${ }^{b}$, Guanjie He*a, ${ }^{*}, c$ and Ivan P. Par$\operatorname{kin} * a$

${ }^{a}$ Christopher Ingold Laboratory, Department of Chemistry, University College London, 20 Gordon Street, London WC1H 0AJ, U.K. Email: g.he@ucl.ac.uk; i.p.parkin@ucl.ac.uk

${ }^{b}$ Electrochemical Innovation Lab, Department of Chemical Engineering, University College London, 20 Gordon Street, London WC1H 0AJ, U.K.

${ }^{c}$ School of Chemistry, University of Lincoln, Brayford Pool, Lincoln, LN6 7TS, UK.

KEYWORDS: zinc-ion batteries, flexible devices, hydrogel electrolytes, cathode stabilised electrolyte, biomass materials

\begin{abstract}
Aqueous zinc-ion batteries (AZIBs) have the potential to be utilised in grid-scale energy storage system owing to their high energy density and cost-effective properties. However, the dissolution of cathode materials and the irreversible extraction of pre-intercalated metal-ions in the electrode materials restrict the stability of AZIBs. Herein, a cathode stabilised zinc-ion batteries (ZIBs) strategy is reported based on a natural biomass polymer sodium alginate as the electrolyte coupling with a Na ${ }^{+}$pre-intercalated $\delta$ - $\mathrm{Na}_{0.65} \mathrm{Mn}_{2} \mathrm{O}_{4} \cdot 1.31 \mathrm{H}_{2} \mathrm{O}$ cathode. The dissociated $\mathrm{Na}^{+}$in alginate after gelation directly stabilises the cathodes by preventing the collapse of layered structures during charge processes. The as-fabricated ZIBs deliver a high capacity showing $305 \mathrm{mAh} \mathrm{g}^{-1}$ at $0.1 \mathrm{~A}$ $\mathrm{g}^{-1}$, even $10 \%$ higher than the ZIBs with an aqueous electrolyte. Further, the hybrid polymer electrolyte possessed excellent coulombic efficiency above $99 \%$ and capacity retention of $96 \%$ within 1000 cycles at $2 \mathrm{~A} \mathrm{~g} \mathrm{~g}^{-1}$. A detailed investigation combining ex-situ experiments uncover the charge storage mechanism and the stability of assembled batteries, confirming the reversible diffusions of both $\mathrm{Zn}^{2+}$ and pre-intercalated $\mathrm{Na}^{+}$. A flexible device of ZIBs fabricated based on vacuum-assisted resin transfer molding (VARTM) possesses an outstanding performance of $160 \mathrm{mAh} \mathrm{g}^{-1}$ at $1 \mathrm{~A} \mathrm{~g} \mathrm{~g}^{-1}$, which illustrates their potential for wearable electronics in mass production.
\end{abstract}

\section{Introduction}

With increasing interest of wearable and implantable electronics in healthcare ${ }^{1}$ and bendable displays ${ }^{2}$, flexible and biocompatible energy storage devices have attracted significant attention. Lithium-ion batteries (LIBs), a technology possessing high energy density ${ }^{3}$, dominated the energy storage sector for several decades ${ }^{4}$. However, the high cost $(\$ 190 / \mathrm{KWh})^{5}$, limited lithium resources, safety issues and the complex manufacturing conditions $^{6}$, are barriers to uptake broader applications ${ }^{7,8}$. As an promising alternative secondary battery, the aqueous zinc-ion battery (AZIB) with mild acidic aqueous electrolyte, is the subject of intense interest attributing to its superior abundance, relatively low $\operatorname{cost}^{9}$, environmental benignity and less toxicity ${ }^{10}$ compared to LIBs. Theoretically, zinc anodes offer a high gravimetric capacity of $820 \mathrm{mAh} \mathrm{g}^{-1}$, and a volumetric capacity of $5855 \mathrm{mAh} \mathrm{cm}{ }^{-3} .{ }^{11}$ The redox potential of $\mathrm{Zn} / \mathrm{Zn}^{2+}$ is $-0.763 \mathrm{~V}$ versus standard hydrogen electrode (SHE), which is suitable for them to use in aqueous electrolyte system.

To date, cathode materials employed for AZIBs can be divided into four categories, manganese-based oxides ${ }^{12-14}$, vanadium-based oxides ${ }^{15-17}$, Prussian blue analogs ${ }^{18,19}$ and other cathode materials including inorganic molybdenum sulphates ${ }^{20}$, molybdenum oxides ${ }^{21,22}$, and organic quinone compounds ${ }^{23,24}$. These materials function as the insertion host for AZIBs, where $\mathrm{Zn}^{2+}$ ions with an ionic radius $(0.74 \AA)$ intercalate into the host structure during the reversible charge/discharge process contributing to a high specific capacity. However, because of the repulsion of the electrostatic interaction between $\mathrm{Zn}^{2+}$ ions and the cathode host, the insertion process is sluggish. Hence, guest species from metal ions with large ionic radius are pre-intercalated into the pristine cathode materials to expend the host channels for insertions. Concerning manganese-based oxides, $\delta$ $\mathrm{MnO}_{2}$ exhibits the layered framework and is beneficial for the modification of pre-intercalated ions. However, during the charge process, the pre-intercalated ions are under the risk of releasing from the host and resulting in the collapse of structures. Wang et al. ${ }^{25-28}$ made a significant contribution in $\mathrm{Mn}$ based cathode materials. $\mathrm{H}^{+}$and $\mathrm{Zn}^{2+}$ intercalation mechanism was proposed, and the as-prepared AZIBs delivered excellent specific capacity above $300 \mathrm{mAh} \mathrm{g}^{-1}$.

Polymer electrolytes in ZIBs, attracting considerable attention, can provide fast ion mobility and solve the safety issues by prohibiting the zinc dendrite penetrating through the separator thus to avoid the short circuit. Regarding the polymer electrolyte in a flexible device, additional mechanical properties of the polymer electrolyte offer the battery with robustness in bending, twisting and cutting tolerance. Previous studies dissolved zinc trifluoromethanesulfonate $\left(\mathrm{Zn}\left(\mathrm{CF}_{3} \mathrm{SO}_{3}\right)_{2}\right)$ into the solid polymers polyethylene oxide $(\mathrm{PEO})^{29}$, polyvinylidene difluoride $(\mathrm{PVDF})^{30}$, polyacrylonitrile (PAN) ${ }^{31}$ and poly(vinyl alcohol) $(\mathrm{PVA})^{32}$, which delivered relatively low ionic conductivities 
from $10^{-4}$ to $10^{-3} \mathrm{~S} \mathrm{~cm}^{-1}$. It is generally agreed that conventional ion transportation in the polymer electrolyte occurs by segmental motion ${ }^{33}$. Similar to lithium-ion transportation in polymer electrolytes, zinc ions in the salt-polymer complex hop from one coordination site of a functional group to another one. ${ }^{34-36}$ The low active segmental motion of $\mathrm{Zn}^{2+}$ ions among the covalent soft chains of solid organic polymer electrolytes results in low ionic conductivity, the inducing of water content, such as forming hydrogel electrolyte, in the polymer electrolyte becomes a prospective way. Recent progress in hydrogel electrolytes for ZIBs complies the advantage of aqueous ZIBs such as a high electron conductivity in the magnitude of $10^{-2} \mathrm{~S} \mathrm{~cm}^{-1},{ }^{37-}$ ${ }^{39}$ however, the ion transport mechanism in the hydrogel ZIBs has not been investigated in details. Zhi et $\mathrm{al}^{40-42}$ indicated that increasing concentrated aqueous electrolytes in hydrogel electrolyte has profound influences on electrochemical stability. Furthermore, Liang et $\mathrm{al}^{43-48}$ comprehensively investigated the mechanism in AZIBs, especially for electrolytes, indicating that a less water content could result from a higher interfacial charge transfer associated with activation energies and $\mathrm{Zn}^{2+}$ desolvation at the cathode interface. In addition, most of the previous work regarding polymer/solid-state electrolytes for different secondary batteries focused on the improvement of ion transport, and the suppression of zinc dendrite for zinc anode ${ }^{49}$, whereas the influence of the electrode materials has been seldomly discussed.

Here, we introduce a robust and flexible ZIBs based on a cathode stabilised hydrogel electrolyte (CSHE) from sodium alginate, accompanying with a sodium pre-intercalated cathode material $\delta-\mathrm{Na}_{0.65} \mathrm{Mn}_{2} \mathrm{O}_{4} \cdot 1.31 \mathrm{H}_{2} \mathrm{O}$. Attribute to the affinity of natural alginates, the alginate hydrogel electrolyte could form when divalent transition metals ions are replaced with $\mathrm{Na}^{+}$ions, where the affinity is in the order of $\mathrm{Pb}^{2+}>\mathrm{Cu}^{2+}>\mathrm{Cd}^{2+}>\mathrm{Ca}^{2+}>\mathrm{Fe}^{2+}>$ $\mathrm{Ni}^{2+}>\mathrm{Zn}^{2+}>\mathrm{Mn}^{2+} .{ }^{50}$ The free dissociated $\mathrm{Na}^{+}$ions in the hydrogel electrolyte prevent the irreversible loss of the pre-intercalated $\mathrm{Na}^{+}$ions in the active materials, and further stabilise the layered structure to achieve an intrinsic specific capacity of 305 $\mathrm{mAh} \mathrm{g}^{-1}$ at $0.1 \mathrm{~A} \mathrm{~g}^{-1}$. To address the energy storage mechanisms of the superior biomass hydrogel ZIBs, the electrodes during cycling were investigated by multiple $e x$-situ characterisations confirming the reversible intercalations of $\mathrm{Zn}^{2+}$, and $\mathrm{Na}^{+}$ions. The as-prepared flexible device also exhibits an excellent stretchability. a

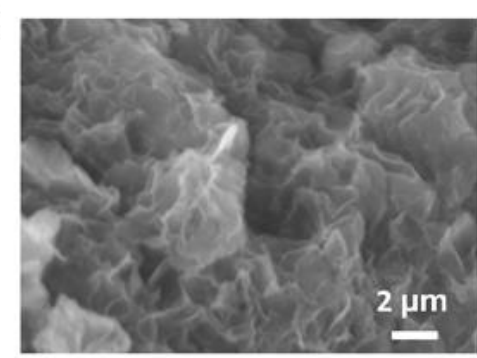

d
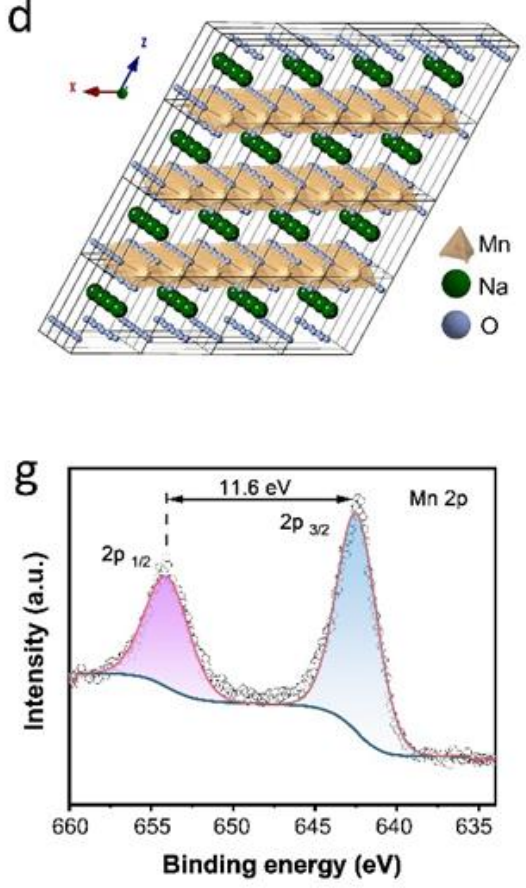

b

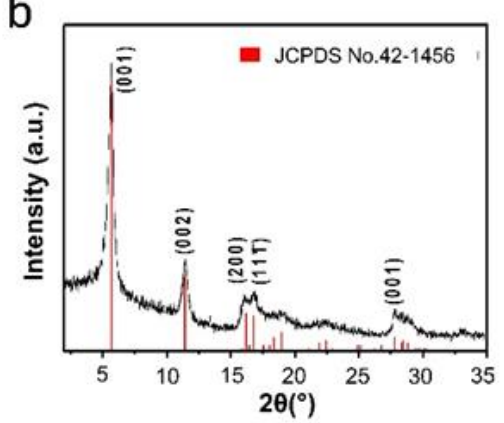

e

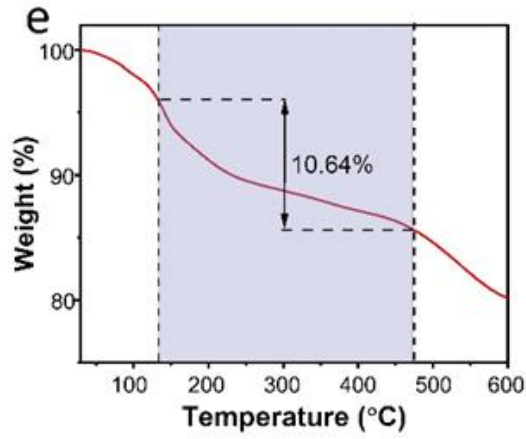

h

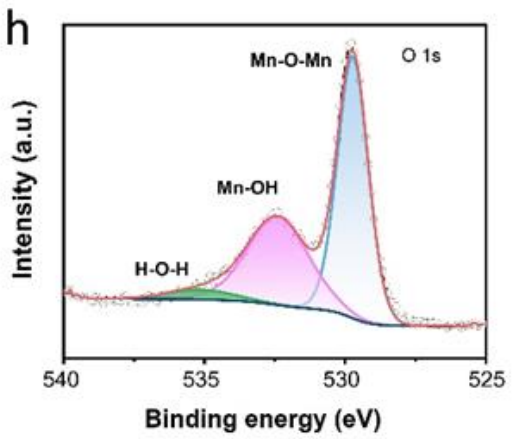

C

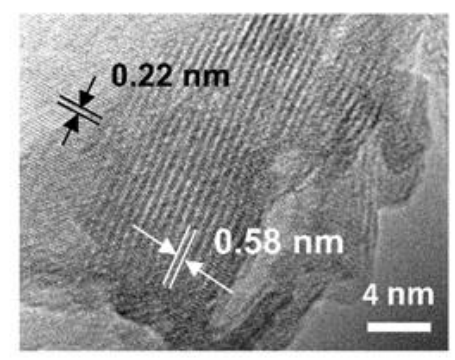

f
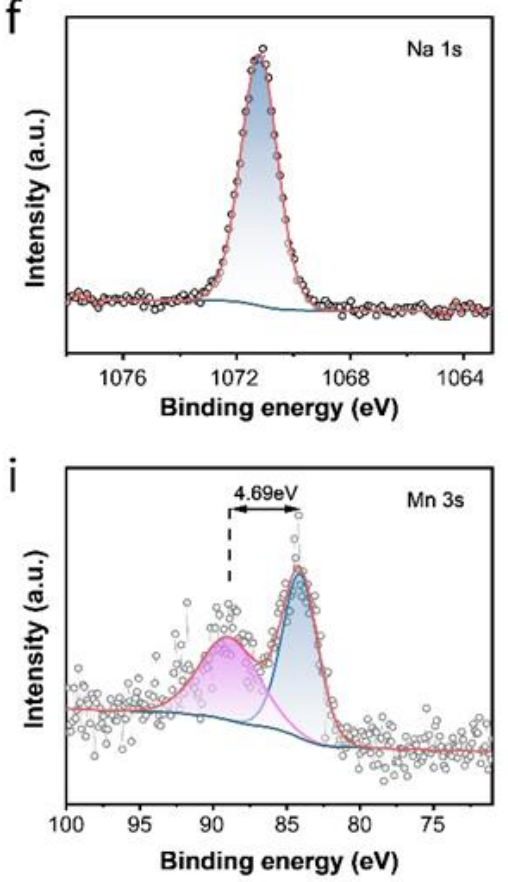
Figure 1. (a) SEM image; (b) XRD pattern; (c) TEM image of as-obtained $\delta$ - $\mathrm{Na}_{0.65} \mathrm{Mn}_{2} \mathrm{O}_{4} \cdot 1.31 \mathrm{H}_{2} \mathrm{O}$, respectively; (d) Crystallographic structure of sodium pre-intercalated $\mathrm{MnO}_{2}$. (Z-axis is perpendicular outwards); (e) TGA results with the temperature up to $600^{\circ} \mathrm{C}$; (f), (g), (h) and (i) XPS spectra for Na 1s, Mn 2p, O 1s and Mn 3s, respectively.

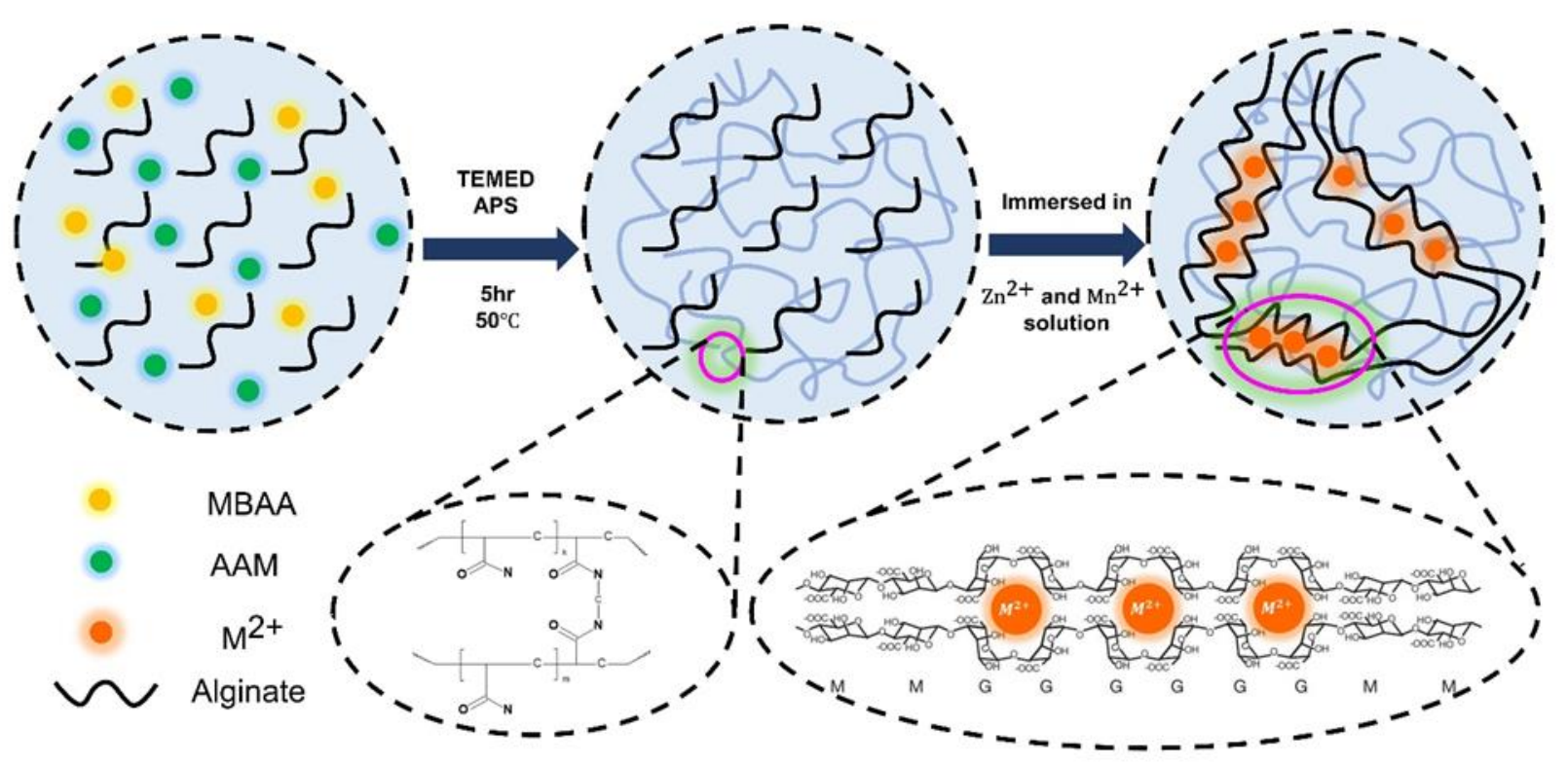

Figure 2. Schematic diagram of the synthetic route of the hybrid polymer electrolyte SA-PAM in three steps. PAM is firstly polymerised by free radical polymerisation forming covalent crosslinking. The gelation of alginate by ionic bonding generates the egg-box shaped structure

\section{Results and discussion}

Hydrated sodium pre-intercalated $\delta-\mathrm{MnO}_{2}$ (NMO) was synthesised by a facile co-precipitation method (details in Supporting Information) and utilised as the active material for the cathode. Scanning electron microscopy (SEM) image (Figure 1a) presents the morphology of the $\mathrm{Na}_{n} \mathrm{Mn}_{2} \mathrm{O}_{4}$ where microscale irregular nanosheets are attained. The X-ray diffraction (XRD) pattern exhibited in Figure $1 \mathrm{~b}$ coincides well with Birnessite $\mathrm{Na}_{0.55} \mathrm{Mn}_{2} \mathrm{O}_{4} \cdot 1.5 \mathrm{H}_{2} \mathrm{O}$ (JCPDS no. 43-1456), where $\mathrm{a}=5.175(3)$ $\AA, \mathrm{b}=2.849(1) \AA, \mathrm{c}=7.338(5) \AA, \alpha=\gamma=90^{\circ}$ and $\beta=$ $103.19(4)^{\circ}, \mathrm{V}=105.3(6) \AA^{3}$. The compositional ratio between pre-intercalated $\mathrm{Na}$ and $\mathrm{Mn}$ determined from the energy-dispersive X-ray spectroscopy (EDS) (Figure S2) is 0.327, hence the molecular formula is $\mathrm{Na}_{0.65} \mathrm{Mn}_{2} \mathrm{O}_{4}$ with an average oxidation state of 3.67 for Mn. Figure S2 also clarifies the homogeneity of the elements $\mathrm{Na}, \mathrm{Mn}$ and $\mathrm{O}$ for the as-obtained cathode materials. Transmission electron microscopy (TEM) was characterised to determine the interlayer spacing and the nanostructure. As shown in Figure 1c, the d-space of the interlayer is 2.22 $\AA$, which is close to the XRD pattern showing the lattice plane of (201). Meanwhile, with the pillars of $\mathrm{Na}^{+}$ions and crystal waters, the measured interlayer spacing is $0.58 \mathrm{~nm}$, which is conducive to ion intercalation. Extra TEM images shown in Figure S11 also reveal the similar interlayer spacing. The detailed crystal structure in Figure $1 \mathrm{~d}$ reveals that the $\mathrm{Na}^{+}$and water molecules are positioned between the Mn-O sheet, in which each $\mathrm{Mn}$ atom connects with six $\mathrm{O}$ atoms forming the octahedra structure. The number of crystal water molecules hydrated in $\mathrm{Na}_{0.65} \mathrm{Mn}_{2} \mathrm{O}_{4}$ was determined by the thermogravimetric analysis
(TGA) (see Figure 1e). The highlighted region is where the crystal water sublimed from 120 to $480^{\circ} \mathrm{C}$, and the $10.64 \%$ weight loss corresponds to 1.31 water molecules, hence the asprepared cathode material is $\mathrm{Na}_{0.65} \mathrm{Mn}_{2} \mathrm{O}_{4}$, matching well with the standard XRD pattern (JCPDS no. 43-1456). X-ray photoelectron spectroscopy (XPS) was utilised to investigate the average oxidation state (AOS) of each element on the surface of the material. $\mathrm{Na}$ is observed as shown in Figure 1f $(\mathrm{Na} 1 \mathrm{~s})$ with a characteristic peak at $1071 \mathrm{eV}$. Mn 2p has two separate peaks with the binding energy difference of $11.6 \mathrm{eV}$, whereas the difference is $4.69 \mathrm{eV}$ for $\mathrm{Mn} 3 \mathrm{~s}$ spectrum. Based on the binding energy difference of the Mn 3s peak, the average oxidation state of $\mathrm{Mn}$ is calculated to be 3.68 according to the formula $\mathrm{AOS}=8.956-1.126 \Delta \mathrm{E}_{\mathrm{s}}{ }^{51}$, where the $\mathrm{Mn}$ valence state is close to the value deduced from the elemental composition. In terms of $\mathrm{O} 1 \mathrm{~s}$ (Figure 1h), the spectrum is convoluted from three corresponding peaks which are assigned to adsorbed water $\mathrm{H}-\mathrm{O}-\mathrm{H}$ (533.4 eV), surface adsorbed oxygen ions Mn-OH (532.2 eV) and lattice oxygen species $\mathrm{Mn}-\mathrm{O}-\mathrm{Mn}(529.8 \mathrm{eV})$, respectively. ${ }^{52}$

To stabilise the active materials in cathodes, a cathode stabilised hydrogel electrolyte (CSHE) was developed based on a biomass material sodium alginate (SA). Sodium alginate is the most commercial alginic acid salt refined from brown seaweeds. It is comprised of mannuronic acid ( $\mathrm{M}$ unit) and guluronic acid ( $\mathrm{G}$ unit), arranging in blocks rich in $\mathrm{G}$ units, blocks rich in $M$ units, and blocks of alternating $G$ and $M$ units. In an aqueous solution, the $\mathrm{G}$ blocks in different alginate chains form ionic crosslinks through divalent cations resulting in a network of alginate hydrogel. ${ }^{53}$ The gelation mechanism is beneficial for 
polymer electrolyte utilised in ZIBs, where hydrogel electrolyte is generated when sodium alginate reacts with $\mathrm{Zn}^{2+}$ or $\mathrm{Mn}^{2+}$. $\mathrm{Na}^{+}$ions dissociated in the hydrogel alleviate the decomposition of the cathode material $\mathrm{Na}_{0.65} \mathrm{Mn}_{2} \mathrm{O}_{4} \cdot 1.31 \mathrm{H}_{2} \mathrm{O}$ naturally during charging process resulting in a high capacity similar to the theoretical value of $\delta-\mathrm{MnO}_{2}$. Covalent crosslinking polyacrylamide (PAM) is incorporated into the hydrogel electrolyte enhancing the polymeric framework, the additional covalent bonds offer a robust 3D porous structure for the hierarchical hydrogel electrolyte sodium alginate-polyacrylamide (SA-PAM). The biomass hydrogel electrolyte was synthesised in three steps (Figure 2) by combining alginate and polyacrylamide to form a co-polymer. Pristine sodium alginate (SA) was firstly dissolved into the deionised water under intensive stirring before adding the acrylamide (AAM) monomer, obtaining a light brown homogeneously mixed solution. The crosslinker N,N'-methylenebisacrylamide (MBAA), the photo-initiator ammonium persulfate (APS) and the accelerator N,N,N',N'-tetramethylethylenediamine (TEMED) were added into themixture sequentially with continuous stirring for $30 \mathrm{~min}$. The homogeneous mixture was then poured into a glass Petri dish followed by rad- ical polarisation at $5^{\circ} \mathrm{C}$ for 5 hours where upon a polyacrylamide hydrogel film was formed by molecular level covalent crosslinkings. Eventually, the network of alginate in the sodium alginate-polyacrylamide (SA-PAM) hydrogel was formed by immersing the well-prepared film into a solution of $1 \mathrm{M} \mathrm{ZnSO}_{4}$ and $0.2 \mathrm{M} \mathrm{MnSO}_{4}$ for 24 hours ensuring alginate $\mathrm{G}$ blocks to form gelation with divalent cations in the aqueous salt solution. Due to the metal ions affinity to the carboxylic acid, $\mathrm{Na}^{+}$was replaced by the divalent cations. Negatively charged carboxylic acid $-\mathrm{COO}^{-}$groups from the $\mathrm{G}$ blocks facilitate ionic bonding with $\mathrm{Zn}^{2+}$ and $\mathrm{Mn}^{2+}$ forming an egg-box shaped structure connecting two alginate chain together. Hydrophilic pendant groups of alginate and polyacrylamide attract and absorb the water molecules by dipole-dipole bonding. Hence, the light transparent alginate polyacrylamide co-polymer electrolyte (see Figure 3a) with two polymer crosslinks referred to as SA-PAM was fabricated. As for comparison, a pristine sodium alginate polymer electrolyte film referred to as SA, was fabricated by a simple evaporating process at $40^{\circ} \mathrm{C}$ followed by the immersing process as illustrated above. a
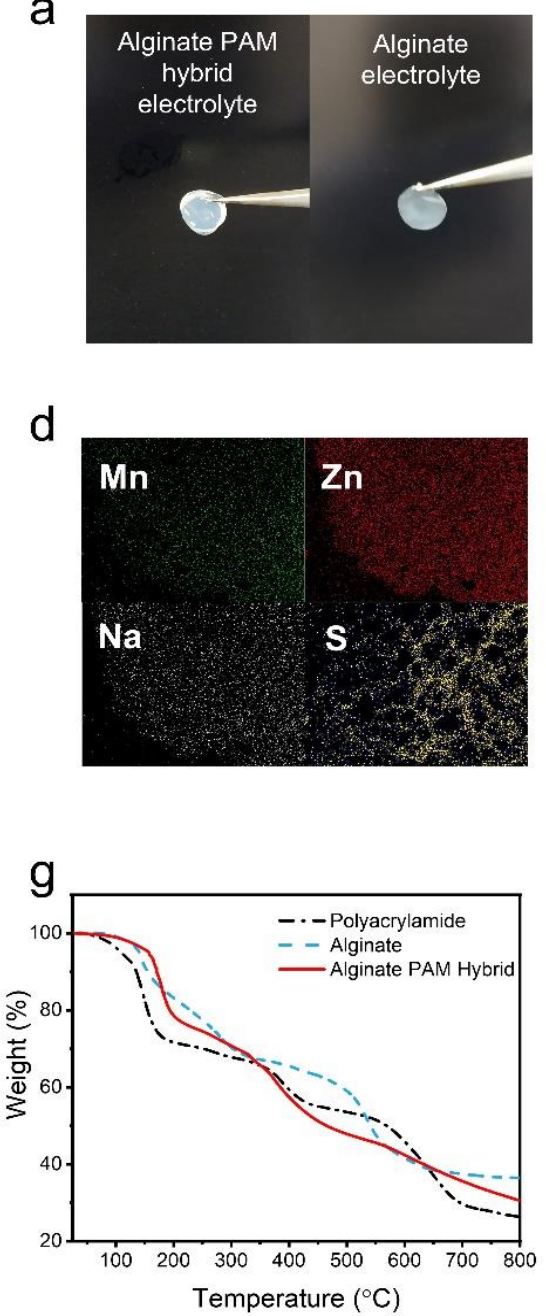

b

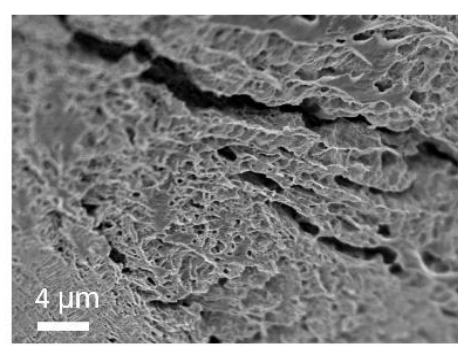

e

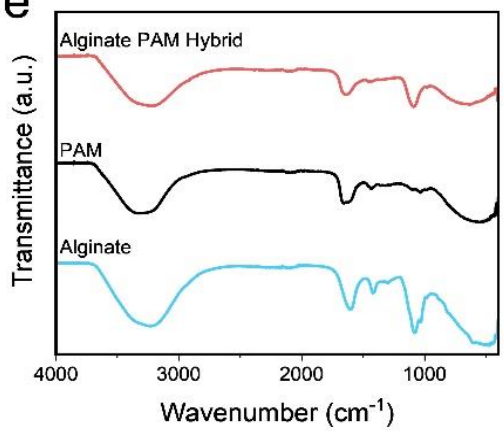

h

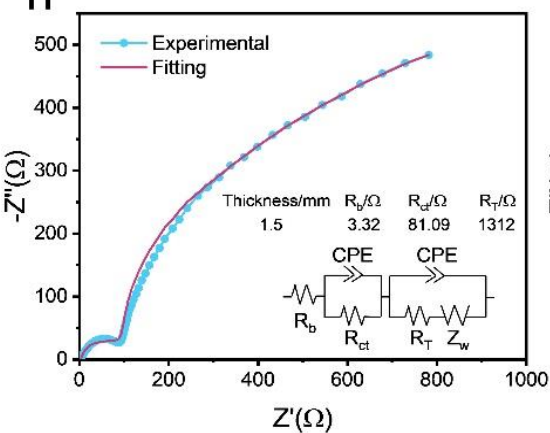

C

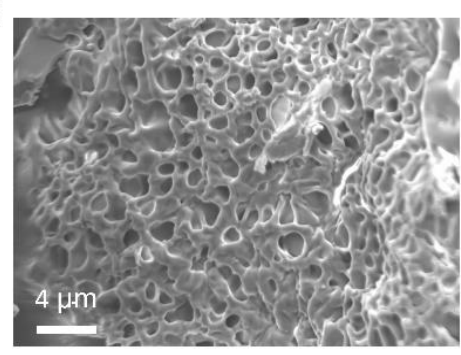

$f$

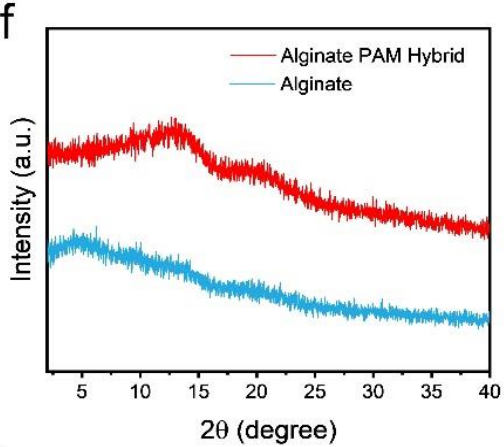

i

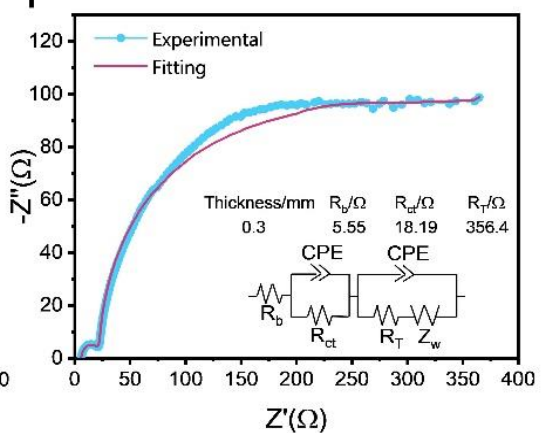

Figure 3 (a) Optical photos for both hybrid and pristine alginate electrolytes; (b) SEM of pristine SA polymer electrolyte; (c) SEM of hybrid SA/PAM polymer electrolyte; (d) EDS mapping of hybrid SA-PAM; (e) FTIR spectra; (f) XRD patterns; (g) TGA analysis; (h) EIS results for SA-PAM under full cell evaluation using a $\mathrm{Na}_{0.65} \mathrm{Mn}_{2} \mathrm{O}_{4}$ cathode; (i) EIS results for SA under full cell test using a $\mathrm{Na}_{0.65} \mathrm{Mn}_{2} \mathrm{O}_{4}$ cathode 

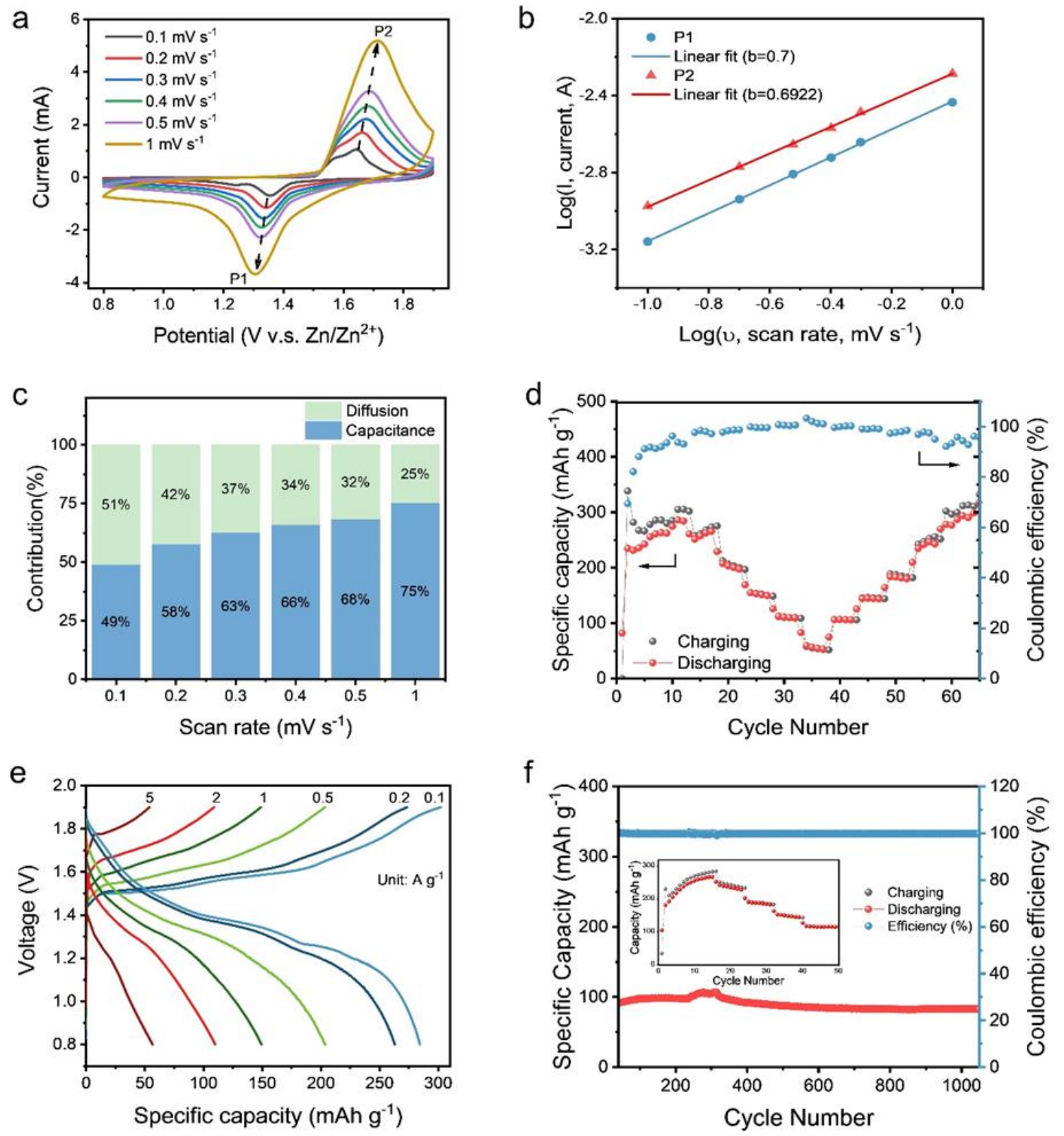

Figure 4 SA-PAM electrolyte under full cell test. (a) CV curves scan rates ranging from $0.1 \mathrm{mV} \mathrm{s}^{-1}$ to $1 \mathrm{mV} \mathrm{s}^{-1}$; (b) diffusioncapacitive contribution with $\log (i) v s \log (v)$ plots of two peaks in CV curves; (c) diffusion-capacitive control contribution presented in the bar chart; (d) Charge/discharge rate performance of current densities from 0.1 to $5 \mathrm{~A} \mathrm{~g}^{-1}$; (e) Galvanostatic charge/discharge profiles for SA-PAM-NMO full cell at different current densities; (f) Long-term cycling stability under the current density of 2 A g${ }^{1}$. The insert plot is the activation process for the first 50 cycles.

In terms of microstructures, although the optical images of SA-PAM and SA have a similar appearance as light-transparent films (Figure 3a), the SEM images reveal that the copolymer SA-PAM possesses a highly porous 3D structures (Figure 3c) compared with less porous structures for the pristine SA electrolyte film (Figure 3b). The porous architecture enables a higher aqueous solution absorption, which may increase the ionic conductivity and mechanical tensile strain ability. The EDS mapping (Figure 3d) reveals that the SA-PAM electrolyte is homogenous under the synthetic method demonstrated above. XPS results (Figure S3) provide further evidence of the ele- ments present on the surface of the hydrogel, for which dissociated $\mathrm{Na}^{+}$is detected. Fourier-transform infrared spectroscopy (FTIR) was utilised (Figure 3e) to exploit the polymerisation mechanism. As for alginate, the characteristic absorption peaks at $1600 \mathrm{~cm}^{-1}$ and $1420 \mathrm{~cm}^{-1}$ represent asymmetric and symmetric -COO stretching owing to the $\mathrm{Zn}^{2+}$ and $\mathrm{Mn}^{2+}$ cations. Bands at $1298 \mathrm{~cm}^{-1}$ for $\mathrm{C}-\mathrm{H}$ deformation, and the other sharp bands at $1076 \mathrm{~cm}^{-1}$ and $1030 \mathrm{~cm}^{-1}$ are assigned for $\mathrm{C}-\mathrm{O}$ stretching in $\mathrm{CH}$ $\mathrm{OH}$ and C-O-C structures, respectively. With regard to PAM, two separate bands at $1649 \mathrm{~cm}^{-1}$ and $1429 \mathrm{~cm}^{-1}$ are for $\mathrm{N}-\mathrm{H}$ bending and $\mathrm{C}-\mathrm{N}$ stretching in -CO-NH-. The band at $1670 \mathrm{~cm}^{-}$ 
${ }^{1}$ should be $\mathrm{C}=\mathrm{O}$ stretching and the $\mathrm{NH}_{2}$ in-plane rocking is detected at $1113 \mathrm{~cm}^{-1}$. As for the co-polymer SA-PAM, after adding PAM to sodium alginate, the broad bands around $3200 \mathrm{~cm}$ 1 for both hybrid polymer SA-PAM and PAM represent the combination of $\mathrm{O}-\mathrm{H}$ and $\mathrm{N}-\mathrm{H}$ stretching vibration, while for pristine alginate, only $\mathrm{O}-\mathrm{H}$ stretching should be observed and the band shift to $3300 \mathrm{~cm}^{-1}$. The hybrid polymer possesses the peaks for both SA and PAM, while transmittances of C-O stretching at $1085 \mathrm{~cm}^{-1}, \mathrm{~N}-\mathrm{H}$ bending at $1647 \mathrm{~cm}^{-1}$ and $\mathrm{C}-\mathrm{N}$ stretching at $1427 \mathrm{~cm}^{-1}$ are all reduced compared with the pristine electrolyte. Regarding the XRD spectrum (Figure 3f), the broad reflection observed instead of the characteristic reflections for both alginate and the hybrid SA-PAM reveals that most regions of those polymer electrolytes are in the amorphous state. Thermal stabilities of the SA and hybrid SA-PAM were determined by TGA from 25 to $800^{\circ} \mathrm{C}$ at a rate of $10^{\circ} \mathrm{C} \mathrm{min}{ }^{-1}$. As displayed in Figure $3 \mathrm{~g}$, there are three pyrolysis stages for the thermal degradation process for both pristine and hybrid polymers. However, the first stage degradation temperature of hybrid SA-PAM is $155^{\circ} \mathrm{C}$ which is higher than that of SA $\left(120^{\circ} \mathrm{C}\right)$ and PAM $\left(110^{\circ} \mathrm{C}\right)$. The combination of ionic and covalent crosslinking process improves the thermal stability of the polymers. The ionic conductivities and inherent resistance shown in Figure $3 \mathrm{~h}$ and $3 \mathrm{i}$ were investigated by electrochemical impedance spectroscopy (EIS). According to the bulk resistance $\left(R_{b}\right)$ of the polymer internal resistance, even pristine alginate polymer electrolyte storing $\mathrm{Zn}^{2+}$ in the "egg box" structure achieves a high ionic conductivity of $3.51 \times 10^{-3} \mathrm{~S} \mathrm{~cm}^{-1}$. Complexing with PAM, the hybrid SA-PAM exhibits a relatively higher ionic conductivity of $2.92 \times 10^{-2} \mathrm{~S} \mathrm{~cm}^{-1}$, which could result in the 3D hierarchical architecture provided by PAM expanding the free volumes for ion transportation.

Cyclic voltammetry (CV) of the hybrid SA-PAM exhibited in Figure 4a was analysed under different scan rates from 0.1 $\mathrm{mV} \mathrm{s}^{-1}$ to $1 \mathrm{mV} \mathrm{s}^{-1}$. At a lower rate of $0.1 \mathrm{mV} \mathrm{s}^{-1}$, two pairs of reduction and oxidation peaks are observed, with reduction peaks at 1.36 and $1.23 \mathrm{~V}$; and oxidation peaks at 1.57 and 1.64 $\mathrm{V}$. With increasing the scan rates, two pairs of redox peaks overlap to a single pair of redox peaks at a higher rate at the voltage of 1.3 and $1.65 \mathrm{~V}$. Comparing with pristine alginate electrolyte SA (Figure S5a), it also maintains the same redox peaks located at the same potentials. To further investigate the kinetic process regarding different electrolytes to the cathode material, diffusion-controlled and capacitive contribution of SA-PAM were evaluated based on two peaks as shown in Figure 4a. Calculations are described in the supporting information.

As presented in Figure 4c, the electrochemical reaction is more reliant on capacitive control when the sweep rate increases from 0.1 to $1 \mathrm{mV} \mathrm{s}^{-1}$. Considering the pristine alginate $\mathrm{SA}$, the kinetic process is dominated by the diffusion-controlled process with $b$ values of 0.66 and 0.69 (Figure S5b). However, as the sweep rate increasing, the entire battery is more affected by the capacitive control, which is consistent with the results of SAPAM (see Figure S5c). Compared with the aqueous battery, CV rate experiments for the $\mathrm{AZIBs}$ were also investigated with the same cathode material $\mathrm{Na}_{0.65} \mathrm{Mn}_{2} \mathrm{O}_{4} \cdot 1.31 \mathrm{H}_{2} \mathrm{O}$ and an aqueous electrolyte of $1 \mathrm{M} \mathrm{ZnSO}_{4}$ and $0.2 \mathrm{M} \mathrm{MnSO}_{4}$ solution. Results (Figure S6c) demonstrate that the aqueous battery is mainly influenced by capacitive control, which is the same as the hybrid SA-PAM batteries. With the increase of hydroxylic groups in the hybrid polymer, SA-PAM is more hydrophilic than the pristine SA and the hybrid electrolyte SA-PAM exhibits a similar capacitive performance to the aqueous battery. Charge/discharge rate performances of SA-PAM, SA and aqueous ZIBs, displayed in Figure 4d, S5d and S6d, respectively, were investigated under stepwise current densities from 0.1 to $5 \mathrm{~A} \mathrm{~g}^{-1}$ with 5 cycles for each current density. Impressively, the SA-PAM battery could achieve $305 \mathrm{mAh} \mathrm{g}^{-1}$ at $0.1 \mathrm{~A} \mathrm{~g}^{-1}$ with an outstanding coulombic efficiency (CE) of $96.2 \%$ compared to $258 \mathrm{mAh}$ $\mathrm{g}^{-1}$ with $91.6 \%$ coulombic efficiency (CE) for the pristine SA battery (see Figure S5d). The rate performance of the hybrid hydrogel battery was measured at current densities of $0.1,0.2$, $0.5,1,2,5 \mathrm{~A} \mathrm{~g}^{-1}$ and exhibiting a good recovery ability with 305 , 273, 203, 152, 110 and $55 \mathrm{mAh} \mathrm{g}^{-1}$, respectively. The specific capacity of SA-PAM at a low current rate $\left(0.1 \mathrm{~A} \mathrm{~g}^{-1}\right)$ is $10 \%$ higher than the aqueous battery $\left(277 \mathrm{mAh} \mathrm{g}^{-1}\right)$, whereas the values of SA-PAM at a higher current $\operatorname{density}\left(5 \mathrm{~A} \mathrm{~g} \mathrm{~g}^{-1}\right)$ is $22 \%$ lower than that of the aqueous battery $\left(70.6 \mathrm{mAh} \mathrm{g}^{-1}\right)$. These differences could be attributed to the interfacial effect and the dissolution of cathode materials in aqueous solutions. A benefit of the solid-solid interface between cathode and electrolyte is that the dissolution of the cathode material into the aqueous electrolyte is inhibited by the hydrogel electrolyte. Meanwhile, the dissociated $\mathrm{Na}^{+}$ions in the hydrogel electrolyte stabilise the crystal structure of the active material preventing the permanent deintercalation of the $\mathrm{Na}^{+}$ions into the electrolyte, hence offering a high capacity compared with the AZIBs at a lower current density. At a higher current density, the incomplete chemical reaction at the solid-solid interface results a less ion transportation compared to the reaction in the aqueous solution, hence resulting in a relatively lower capacity.

Galvanostatic charge/discharge profiles for SA-PAM at different current densities are illustrated in Figure 4e. During the discharge process at $0.1 \mathrm{~A} \mathrm{~g} \mathrm{~g}^{-1}$, the first plateau positioned at 1.4 $\mathrm{V}$ is attributed to $\mathrm{H}^{+}$insertion; and the second plateau around $1.2 \mathrm{~V}$ is attributed to $\mathrm{Zn}^{2+}$ insertion ${ }^{38}$. For the charging process, corresponding deintercalations of $\mathrm{H}^{+}$and $\mathrm{Zn}^{2+}$ are assigned to the plateau at $1.55 \mathrm{~V}$ and $1.7 \mathrm{~V}$. Both the pristine and hybrid hydrogel electrolyte batteries possess the plateaus at the same voltages as the aqueous battery, which implies that there is no obvious ion-transport reduction by utilising these hydrogels even for the pristine alginate (Figure S5e and S6e). Long-term cycling stability was determined under $2 \mathrm{~A} \mathrm{~g} \mathrm{~g}^{-1}$ for SA-PAM, SA and aqueous batteries (see Figure 4f, S5f and S6f) accompanying with the electrolyte $3 \mathrm{M} \mathrm{ZnSO}_{4}$ and $0.2 \mathrm{M} \mathrm{MnSO}_{4}$. An activation applied at the beginning of the cycling test is to entirely polarise the solid-solid interface between the cathode and hydrogel electrolyte SA-PAM exhibited a superior 

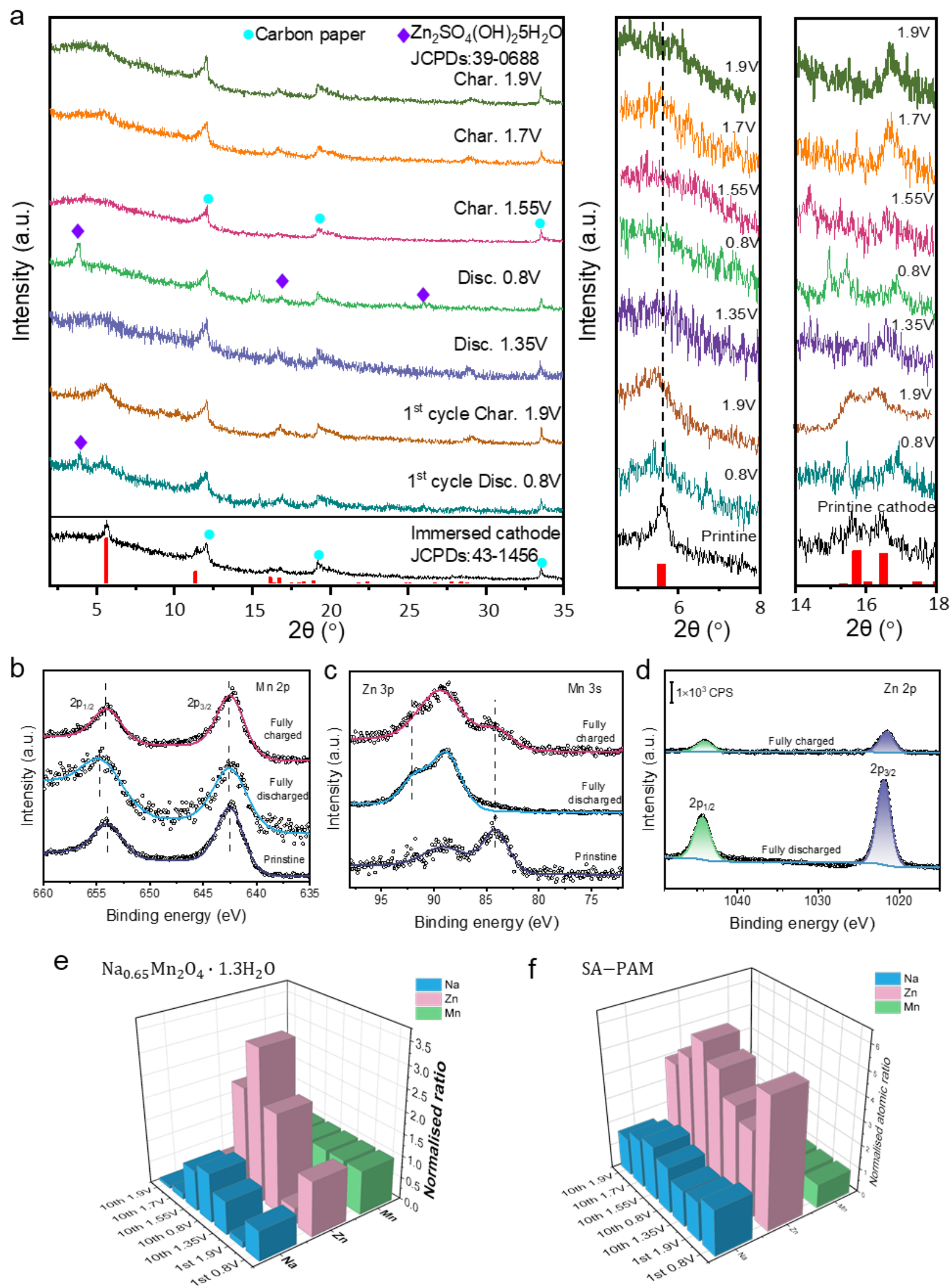

Figure 5 (a) Ex-situ XRD spectra for the $\mathrm{Na}_{0.65} \mathrm{Mn}_{2} \mathrm{O}_{4} \cdot 1.31 \mathrm{H}_{2} \mathrm{O}$ cathode under the full cell assembly with SA-PAM at different states of charge/discharge. Right two plots are amplified plots for peak (001); and (200) and (001); (b), (c), (d) ex-situ XPS spectra for Mn 2p, Mn 3s and Zn 2p respectively at fully charged and discharged states; (e) EDS results of elemental compositions with normalised ratios (with respect to $\mathrm{Mn}$ ) for cathode material NMO; (f) EDS results of elemental compositions normalised with respect to Mn for polymer electrolyte SA-PAM. 
capacity retention of $96 \%$ over 1000 cycles comparing with $70.1 \%$ capacity retention for pristine SA and $92 \%$ for aqueous electrolyte. Because of the weak electrostatic attraction-ionic bonding and the low ionic conductivity of SA, pristine SA electrolyte is not sufficient stable to reach a high capacity close to the intrinsic value. The fluctuation appeared in these figures are influenced by the ambient temperature change. Zn plating/stripping performance of the $\mathrm{Zn} / / \mathrm{Zn}$ symmetric cell shown in Figure S8 also indicates the stability with respect to aqueous electrolyte. SA-PAM maintains a stable performance throughout the 250-hour test, whereas the aqueous electrolyte could only keep 130 hours. As to verify the stabilising effect of additional $\mathrm{Na}^{+}$ ions from alginate-PAM hydrogel electrolyte, both $\mathrm{CV}$ and cycling tests have performed under the electrolyte $3 \mathrm{M} \mathrm{ZnSO}$ $0.2 \mathrm{MnSO}_{4}$ and $0.2 \mathrm{Na}_{2} \mathrm{SO}_{4}$. As shown in the $\mathrm{CV}$ plot (Figure $\mathrm{S} 15 \mathrm{a})$, there is no additional redox peaks compared with SAPAM and aqueous ZIBs (See Figure 4a and Figure S6a respectively). Regarding the charge/discharge cycling performance, the battery with additional sodium salt delivers a capacity retention of $95.2 \%$ (Figure S15b), greater than the one without sodium salt.

Combined ex-situ XRD, XPS and SEM-EDS analysis were performed to investigate the energy storage mechanism for the hydrogel ZIBs at the specific voltage as shown in Figure S13. Crystal structural evolution of $\mathrm{Na}_{0.65} \mathrm{Mn}_{2} \mathrm{O}_{4}$ in the hydrogel ZIB was investigated by ex-situ XRD measured at specific state of charge (SOC) from $0.8 \mathrm{~V}$ to $1.9 \mathrm{~V}$ for the $1^{\text {st }}$ and $10^{\text {th }}$ cycles under the current density of $0.1 \mathrm{~A} \mathrm{~g} \mathrm{~g}^{-1}$. According to the XRD patterns shown in Figure 5a, there is no significant phase variation during the charge/discharge processes, besides only $1^{\circ}$

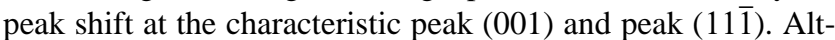
hough a small phase shift is observed, the entire layered structure remains stable during the charge/discharge process. Owing to $\mathrm{Zn}^{2+}$ intercalation/deintercalation mechanism, intensity of these characteristic peaks is reduced during cycling. However, because of the $\mathrm{Na}^{+}$from the biomass sodium alginate, there is a supplement of $\mathrm{Na}^{+}$for the pre-intercalated $\delta$ $\mathrm{Na}_{0.65} \mathrm{Mn}_{2} \mathrm{O}_{4} \cdot 1.31 \mathrm{H}_{2} \mathrm{O}$ during cycling. Therefore, these characteristic peaks can still be recognized after 10 cycles for SAPAM comparing with the ex-situ spectra for aqueous ZIBs shown in Figure S14, where the peak (001) has almost disappeared at $10^{\text {th }}$ cycle at $1.9 \mathrm{~V}$. Similar to aqueous $\mathrm{ZIBs}$, the flower-like $\mathrm{Zn}_{4} \mathrm{SO}_{4}(\mathrm{OH})_{6} \cdot 5 \mathrm{H}_{2} \mathrm{O}$ is observed from SEM images (Table S1), while the depositions disappear during the charging process, which reveals the reversible $\mathrm{Zn}^{2+}$ intercalations. Quantitative analysis of EDS also reveals reversible ion transportations in cathodes (Figure 5e), where the contents of both $\mathrm{Na}^{+}$ and $\mathrm{Zn}^{2+}$ increase in the discharge process and decrease in the charge process. Under the same electric field, $\mathrm{Na}^{+}$in the biomass electrolyte simultaneously insert into the cathode with $\mathrm{Zn}^{2+}$ serving as the supplement to the pre-intercalated $\mathrm{Na}^{+}$in the cathode suppressing the $\mathrm{Na}^{+}$extraction during charging/discharging. Theoretically, the amount of $\mathrm{Na}^{+}$and $\mathrm{Zn}^{2+}$ in the hydrogel electrolyte SA-PAM (Figure 5f) is expected in contrast with the cathode. However, because of the abundant $\mathrm{Na}^{+}$and $\mathrm{Zn}^{2+}$ exhibited in the electrolyte, there is no notable intensity variation during the charge/discharge processes. Dissociated $\mathrm{Na}^{+}$in the hydrogel stabilises the cathode material by intercalating into the interlayer, hence avoiding the collapse of the crystal structure. Regarding the spectra of Mn $2 p$ (Figure $5 b$ ), there is a $1.0 \mathrm{eV}$ peak shift for the doublet peak at the binding energy of $665.0 \mathrm{eV}$ from fully discharged state to fully charged state. Spectra of Mn 3s is used to determine the variation of average oxidation state of Mn during cycling, whereas the overlaps of $\mathrm{Zn} \mathrm{3p}$ at 80-95 eV make it complicated to identify the exact valence state. However, the disappearance of the characteristic peak at $84 \mathrm{eV}$ of Mn 3s in the fully discharged state confirms the oxidation state change of Mn during the charging/discharging process. The profile of $\mathrm{Zn} 2 \mathrm{p}$ in Figure 5e provides the evidences of formation of $\mathrm{Zn}_{4} \mathrm{SO}_{4}(\mathrm{OH})_{6} \cdot 5 \mathrm{H}_{2} \mathrm{O}$ where the area enclosed by the $\mathrm{Zn} 2 \mathrm{p} 3 / 2$ peak $(1022.2 \mathrm{eV})$ in the fully discharged state is greater than that in the fully discharged state (1021.6 $\mathrm{eV})$.

Therefore, the chemical reaction could be illustrated as below by combining the intercalation and chemical conversion reactions.

$$
\begin{aligned}
& \text { At the cathode: } \mathrm{Zn}^{2+}+2 \mathrm{e}^{-}+2 \mathrm{MnO}_{2} \leftrightarrow \mathrm{ZnMn}_{2} \mathrm{O}_{4} \\
& 3 \mathrm{Zn}^{2+}+6 \mathrm{OH}^{-}+\mathrm{ZnSO}_{4}+5 \mathrm{H}_{2} \mathrm{O} \leftrightarrow \mathrm{ZnSO}_{4}\left[\mathrm{Zn}(\mathrm{OH})_{2}\right]_{3} \cdot 5 \mathrm{H}_{2} \mathrm{O} \\
& \text { At the anode: } \mathrm{Zn} \leftrightarrow \mathrm{Zn}^{2+}+2 \mathrm{e}^{-}
\end{aligned}
$$

Encouraged by the impressive cathode stabilised hydrogel properties, a flexible device was fabricated based on the vacuum-assisted resin transfer moulding (VARTM) technique ${ }^{54,55}$. This approach lends itself to scale-up from the experimental demonstrator to the industrial mass production. Carbon fibre fabrics were selected as the current collector to provide flexibility. Each layer as shown in Figure 6a was assembled using a simple lamination process. However, aiming to apply the VARTM and avoid short-circuit, a layer of filter paper was infused into the polymer electrolyte inserted between the electrodes. When the vacuum was applied, the hydrogel electrolyte SA-PAM was fully immersed through the electrodes and filled the entire battery. A layer of peel ply and breather were positioned on top of the laminates assembly to provide extra air vent for the as-assembled batteries. The rest process for polymerisation is the same as illustrated in Figure 2. The length of the resultant device is approximately $7 \mathrm{~cm}$, which is of a scale suitable for portable electronic devices. By way of demonstration, connecting two devices in series, a light-emitting diode (LED) display panel can be powered by the device (Figure 6b). As demonstrated in Figure $6 \mathrm{c}$, the $1.39 \mathrm{~V}$ open-circuit potential of the flexible ZIB is the same as the coin cell assembly, which supports the approach as a suitable fabrication strategy. In order to demonstrate physical robustness of the device, the flexible ZIBs were connected to a digital temperature and humidity meter to act as an electrical load and subjected to mechanical stress. Bending, twisting and cutting was performed (Figure $6 \mathrm{f}, 6 \mathrm{~g}$ and $6 \mathrm{~h}$ ), and the ability to power the meter was unaffected. To further assess the device's electrochemical performance, a galvanostatic charge/discharge experiment was performed (Figure $6 b$ ). At a current density of $1 \mathrm{~A} \mathrm{~g}^{-1}$, a surprisingly high specific capacity of $160 \mathrm{mAh} \mathrm{g}^{-1}$ was obtained for a device-level demonstrator and is of a consistent level to that obtained from coin cell testing (Figure 4d). Tensile test proceeded (see Figure S9) also indicates an excellent stretchability for the hydrogel electrolyte. A SA-PAM with carbon fabrics composite was mechanically robust and electrochemically reliable. Supplementary Videos attached further demonstrate the device's physical flexibility and robustness. 
a

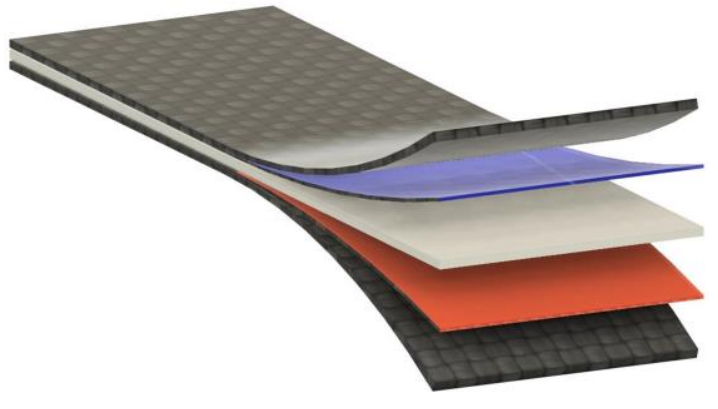

b Carbon cloth

Zinc paste

Polymer with

filter paper

NMO paste

Carbon cloth

C

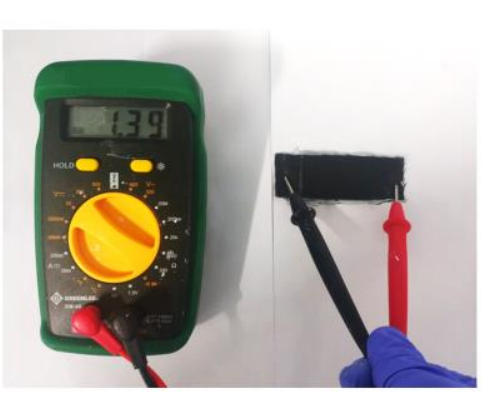

f

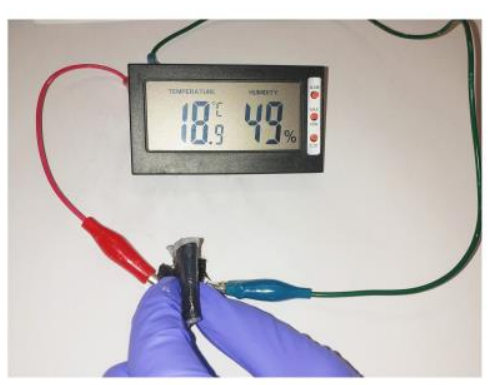

d

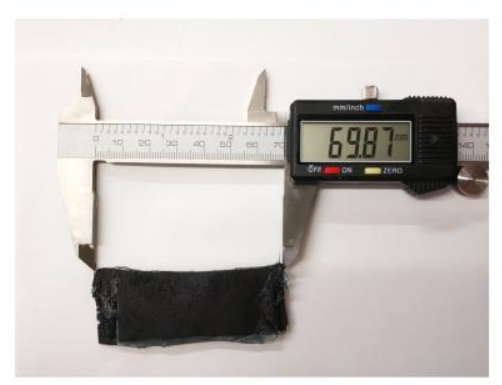

g

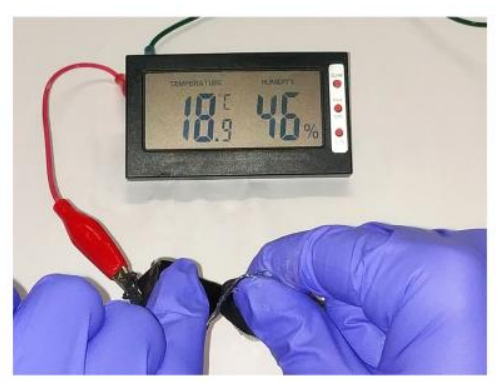

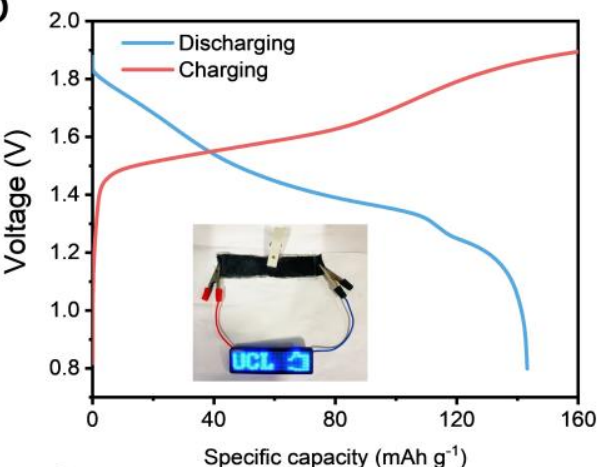

e

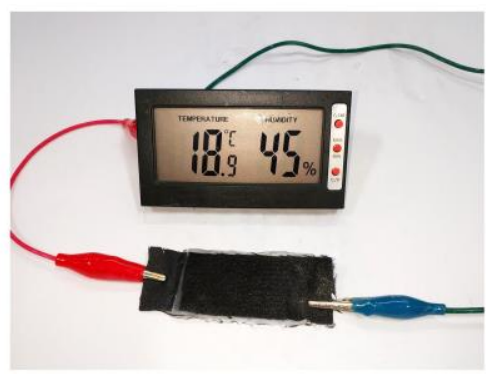

h

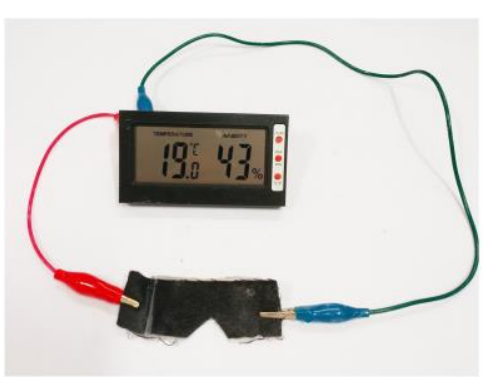

Figure 6 (a) Schematic illustration of the flexible device; (b) galvanostatic charge-discharge results of the flexible device at a current density of $1 \mathrm{~A} \mathrm{~g} \mathrm{~g}^{-1}$. The internal graph shows the LED board powered by the devices connected in series; (c) open-circuit potential of the as prepared device; (d) dimension of the device; (e) initial state of the device which can power a digital temperature-humidity meter; (f) bending the device; (g) twisting the device; (h) cutting the device.

\section{Conclusion}

A cathode-stabilised hydrogel-state ZIB was fabricated by combining a layered $\delta-\mathrm{Na}_{0.65} \mathrm{Mn}_{2} \mathrm{O}_{4} \cdot 1.31 \mathrm{H}_{2} \mathrm{O}$ and a cathode-stabilised hydrogel electrolyte (CSHE). The pristine biodegradable alginate electrolyte SA exhibits a specific capacity of 258 $\mathrm{mAh} \mathrm{g}^{-1}$, while the hybrid hydrogel electrolyte SA-PAM further enhances the electrochemical stability and mechanical properties, offering the a superior specific capacity and ionic conductivity of $305 \mathrm{mAh} \mathrm{g}^{-1}$ and $2.92 \times 10^{-2} \mathrm{~S} \mathrm{~cm}^{-1}$, respectively. The ex-situ tests in XRD, XPS and EDS employed precisely investigate the electrochemical reactions for hydrogel $\mathrm{ZIBs}$. The reversible intercalations of $\mathrm{Zn}^{2+}$ and $\mathrm{Na}^{+}$observed on the cathode materials reveal that dissociated $\mathrm{Na}^{+}$in the hydrogel electrolyte alleviate the collapse of the active material's crystal structure, thus offering a superior specific capacity. The fabricated flexible device also possesses a specific capacity of $160 \mathrm{mAh} \mathrm{g}^{-1}$ under $1 \mathrm{~A} \mathrm{~g}^{-1}$, as well as superior mechanical properties being resistant to binding, twisting and cutting.

\section{Supporting Information}

Supporting Information Available: Experimental details of material fabrication and characterisation, additional SEM-EDS results, additional XPS spectra, additional CV and EIS profile of symmetric cell $\mathrm{Zn} / / \mathrm{Zn}$, electrochemical performance for pristine SA and aqueous ZIBs, Zn plating/ stripping performance of the symmetric cell, tensile test of the flexible device, additional XRD spectrum, additional TEM images, ex-situ SEM-EDS results for cathode and the hydrogel electrolyte, a table of recent hydrogel electrolytes for ZIBs, and the video demonstrating the flexibility of the device fabricated.

\section{ACKNOWLEDGMENT}

The authors would like to thank Engineering and Physical Sciences Research Council (EPSRC, EP/L015862/1, EP/R023581/1), STFC Batteries Network (ST/R006873/1), RSC Mobility Grant (M19-7656) for funding support and China Scholarship Council/University College London for the joint PhD scholarship.

\section{ASSOCIATED CONTENT}




\section{ABBREVIATIONS}

CSHE: cathode-stabilised hydrogel electrolyte

\section{REFERENCES}

(1) Lee, G. H.; Moon, H.; Kim, H.; Lee, G. H.; Kwon, W.; Yoo, S.; Myung, D.; Yun, S. H.; Bao, Z.; Hahn, S. K. Multifunctional Materials for Implantable and Wearable Photonic Healthcare Devices. Nat. Rev. Mater. 2020, 5 (5), 149-165. https://doi.org/10.1038/s41578-019-0167-3.

(2) Myny, K. The Development of Flexible Integrated Circuits Based on Thin-Film Transistors. Nat. Electron. 2018, 1 (1), 30-39. https://doi.org/10.1038/s41928-017-0008-6.

(3) Kim, T.; Song, W.; Son, D. Y.; Ono, L. K.; Qi, Y. Lithium-Ion Batteries: Outlook on Present, Future, and Hybridized Technologies. J. Mater. Chem. A 2019, 7 (7), 2942-2964. https://doi.org/10.1039/C8TA10513H.

(4) Armand, M. Nature Lithium Battery. Nature 2001, 414 (November), 359-367. https://doi.org/10.1038/35104644.

(5) Frith, J. Lithium-Ion Batteries: The Incumbent Technology. BloombergNEF 2019, 1, 1-21.

(6) Zhou, G.; Li, F.; Cheng, H. M. Progress in Flexible Lithium Batteries and Future Prospects. Energy Environ. Sci. 2014, 7 (4), 1307-1338. https://doi.org/10.1039/c3ee43182g.

(7) Wang, Y.; Yi, J.; Xia, Y. Recent Progress in Aqueous Lithium-Ion Batteries. Adv. Energy Mater. 2012, 2 (7), 830 840. https://doi.org/10.1002/aenm.201200065.

(8) Etacheri, V.; Marom, R.; Elazari, R.; Salitra, G.; Aurbach, D. Challenges in the Development of Advanced LiIon Batteries: A Review. Energy Environ. Sci. 2011, 4 (9), 3243-3262. https://doi.org/10.1039/c1ee01598b.

(9) Lu, J.; Li, Y.; Fu, J.; Amine, K.; Zhong, C.; Chen, Z.; $\mathrm{Hu}, \mathrm{W}$; Wu, T. Recent Advances in Flexible Zinc-Based Rechargeable Batteries. Adv. Energy Mater. 2018, 9 (1), 1802605. https://doi.org/10.1002/aenm.201802605.

(10) Heller, A. Potentially Implantable Miniature Batteries. Anal. Bioanal. Chem. 2006, 385 (3), 469-473. https://doi.org/10.1007/s00216-006-0326-4.

(11) Song, M.; Tan, H.; Chao, D.; Fan, H. J. Recent Advances in Zn-Ion Batteries. Adv. Funct. Mater. 2018, 28 (41), 127. https://doi.org/10.1002/adfm.201802564.

(12) Wang, F.; Hu, E.; Sun, W.; Gao, T.; Ji, X.; Fan, X.; Han, F.; Yang, X. Q.; Xu, K.; Wang, C. A Rechargeable Aqueous Zn2+-Battery with High Power Density and a Long CycleLife. Energy Environ. Sci. 2018, 11 (11), 3168-3175. https://doi.org/10.1039/c8ee01883a.

(13) Pan, H.; Shao, Y.; Yan, P.; Cheng, Y.; Han, K. S.; Nie, Z.; Wang, C.; Yang, J.; Li, X.; Bhattacharya, P.; Mueller, K. T.; Liu, J. Reversible Aqueous Zinc/Manganese Oxide Energy Storage from Conversion Reactions. Nat. Energy 2016, 1 (April), 1-7. https://doi.org/10.1038/nenergy.2016.39.

(14) Zhang, N.; Cheng, F.; Liu, J.; Wang, L.; Long, X.; Liu, X.; Li, F.; Chen, J. Rechargeable Aqueous Zinc-MaZhang, N., Cheng, F., Liu, J., Wang, L., Long, X., Liu, X., ... Chen, J. (2017). Rechargeable Aqueous Zinc-Manganese Dioxide Batteries with High Energy and Power Densities. Nature Communications, 8(1), 1-9. Https://Doi.Org/10.103. Nat. Commun. 2017, 8 (1), 1-9. https://doi.org/10.1038/s41467-017-00467-x.

(15) Wang, L.; Huang, K. W.; Chen, J.; Zheng, J. Ultralong Cycle Stability of Aqueous Zinc-Ion Batteries with Zinc Vanadium Oxide Cathodes. Sci. Adv. 2019, 5 (10), 1-11. https://doi.org/10.1126/sciadv.aax4279.

(16) Li, J.; Mccoll, K.; Lu, X.; Sathasivam, S.; Dong, H.; Kang, L.; Li, Z.; Zhao, S.; Kafizas, G.; Wang, R.; Brett, D. J.
L.; Shearing, P. R.; Corà, F.; He, G.; Carmalt, C. J.; Ivan, P. Materials in Aqueous Zinc-Ion Batteries. 2020, 2000058, 0-48. https://doi.org/10.1002/aenm.202000058.

(17) Yang, Y.; Tang, Y.; Fang, G.; Shan, L.; Guo, J.; Zhang, W.; Wang, C.; Wang, L.; Zhou, J.; Liang, S. Li+ Intercalated $\mathrm{V} 2 \mathrm{O} 5 \cdot: \mathrm{N} H 2 \mathrm{O}$ with Enlarged Layer Spacing and Fast Ion Diffusion as an Aqueous Zinc-Ion Battery Cathode. Energy Environ. Sci. 2018, 11 (11), 3157-3162. https://doi.org/10.1039/c8ee01651h.

(18) Ma, L.; Chen, S.; Long, C.; Li, X.; Zhao, Y.; Liu, Z.; Huang, Z.; Dong, B.; Zapien, J. A.; Zhi, C. Achieving HighVoltage and High-Capacity Aqueous Rechargeable Zinc Ion Battery by Incorporating Two-Species Redox Reaction. Adv. Energy Mater. 2019, 1902446, 1-10. https://doi.org/10.1002/aenm.201902446.

(19) Zhang, L.; Chen, L.; Zhou, X.; Liu, Z. Towards HighVoltage Aqueous Metal-Ion Batteries beyond $1.5 \mathrm{~V}$ : The Zinc/Zinc Hexacyanoferrate System. Adv. Energy Mater. 2015, 5 (2), 1-5. https://doi.org/10.1002/aenm.201400930.

(20) Liang, H.; Cao, Z.; Ming, F.; Zhang, W.; Anjum, D. H.; Cui, Y.; Cavallo, L.; Alshareef, H. N. Aqueous Zinc-Ion Storage in MoS 2 by Tuning the Intercalation Energy. Nano $\begin{array}{llll}\text { Lett. } & \mathbf{2 0 1 9}, & 19 & \text { (5), }\end{array}$ https://doi.org/10.1021/acs.nanolett.9b00697.

(21) Li, H.; McRae, L.; Firby, C. J.; Elezzabi, A. Y. Rechargeable Aqueous Electrochromic Batteries Utilizing Ti-Substituted Tungsten Molybdenum Oxide Based Zn 2+ Ion Intercalation Cathodes. $A d v$. Mater. 2019, 31 (15), 1-9. https://doi.org/10.1002/adma.201807065.

(22) He, X.; Zhang, H.; Zhao, X.; Zhang, P.; Chen, M.; Zheng, Z.; Han, Z.; Zhu, T.; Tong, Y.; Lu, X. Stabilized Molybdenum Trioxide Nanowires as Novel Ultrahigh-Capacity Cathode for Rechargeable Zinc Ion Battery. Adv. Sci. 2019, 6 (14), 2-9. https://doi.org/10.1002/advs.201900151.

(23) Zhao, Q.; Huang, W.; Luo, Z.; Liu, L.; Lu, Y.; Li, Y.; Li, L.; Hu, J.; Ma, H.; Chen, J. High-Capacity Aqueous Zinc Batteries Using Sustainable Quinone Electrodes. Sci. Adv. 2018, 4 (3), 1761. https://doi.org/10.1126/sciadv.aao1761.

(24) Kundu, D.; Oberholzer, P.; Glaros, C.; Bouzid, A.; Tervoort, E.; Pasquarello, A.; Niederberger, M. Organic Cathode for Aqueous Zn-Ion Batteries: Taming a Unique Phase Evolution toward Stable Electrochemical Cycling. Chem. Mater. 2018, 30 (11), 3874-3881. https://doi.org/10.1021/acs.chemmater.8b01317.

(25) Wang, J.; Wang, J. G.; Qin, X.; Wang, Y.; You, Z.; Liu, H.; Shao, M. Superfine MnO2 Nanowires with Rich Defects Toward Boosted Zinc Ion Storage Performance. ACS Appl. Mater. Interfaces 2020, 12 (31), 34949-34958. https://doi.org/10.1021/acsami.0c08812.

(26) Wang, J.; Wang, J. G.; Liu, H.; Wei, C.; Kang, F. Zinc Ion Stabilized MnO2 Nanospheres for High Capacity and Long Lifespan Aqueous Zinc-Ion Batteries. J. Mater. Chem. A 2019, 7 (22), 13727-13735. https://doi.org/10.1039/c9ta03541a.

(27) Wang, J.; Wang, J. G.; Liu, H.; You, Z.; Wei, C.; Kang, F. Electrochemical Activation of Commercial MnO Microsized Particles for High-Performance Aqueous Zinc-Ion Batteries. $J$. Power Sources 2019, 438 (August), 226951. https://doi.org/10.1016/j.jpowsour.2019.226951.

(28) Guo, S.; Liang, S.; Zhang, B.; Fang, G.; Ma, D.; Zhou, J. Cathode Interfacial Layer Formation via in Situ Electrochemically Charging in Aqueous Zinc-Ion Battery. ACS Nano 2019 , 13 https://doi.org/10.1021/acsnano.9b07042. 
(29) Karan, S.; Sahu, T. B.; Sahu, M.; Mahipal, Y. K.; Agrawal, R. C. Characterization of Ion Transport Property in Hot-Press Cast Solid Polymer Electrolyte (SPE) Films: [PEO: $\mathrm{Zn}(\mathrm{CF} 3 \mathrm{SO} 3) 2]$. Ionics (Kiel). 2017, 23 (10), 2721-2726. https://doi.org/10.1007/s11581-017-2036-7.

(30) Kumar, G. G.; Sampath, S. Electrochemical Characterization of Poly(Vinylidenefluoride)-Zinc Triflate Gel Polymer Electrolyte and Its Application in Solid-State Zinc Batteries. Solid State Ionics 2003, 160 (3-4), 289-300. https://doi.org/10.1016/S0167-2738(03)00209-1.

(31) Girish Kumar, G.; Sampath, S. Spectroscopic Characterization of a Gel Polymer Electrolyte of Zinc Triflate and Polyacrylonitrile. Polymer (Guildf). 2004, 45 (9), 2889-2895. https://doi.org/10.1016/j.polymer.2004.02.053.

(32) Yu, M.; Zeng, Y.; Zhang, X.; Wu, Y.; Lu, X.; Yi, J.; Tong, Y.; Meng, Y. Achieving Ultrahigh Energy Density and Long Durability in a Flexible Rechargeable Quasi-Solid-State Zn-MnO 2 Battery. Adv. Mater. 2017, 29 (26), 1700274. https://doi.org/10.1002/adma.201700274.

(33) Long, L.; Wang, S.; Xiao, M.; Meng, Y. Polymer Electrolytes for Lithium Polymer Batteries. J. Mater. Chem. A 2016, 4 (26), 10038-10039. https://doi.org/10.1039/c6ta02621d.

(34) Wu, K.; Huang, J.; Yi, J.; Liu, X.; Liu, Y.; Wang, Y.; Zhang, J.; Xia, Y. Recent Advances in Polymer Electrolytes for Zinc Ion Batteries: Mechanisms, Properties, and Perspectives. Adv. Energy Mater. 2020, 1903977, 1-32. https://doi.org/10.1002/aenm.201903977.

(35) Xue, Z.; He, D.; Xie, X. Poly(Ethylene Oxide)-Based Electrolytes for Lithium-Ion Batteries. J. Mater. Chem. A 2015, 3 (38), 19218-19253. https://doi.org/10.1039/c5ta03471j.

(36) Manthiram, A.; Yu, X.; Wang, S. Lithium Battery Chemistries Enabled by Solid-State Electrolytes. Nat. Rev. Mater. 2017, 2 (4), 1-16. https://doi.org/10.1038/natrevmats.2016.103.

(37) Li, H.; Han, C.; Huang, Y.; Huang, Y.; Zhu, M.; Pei, Z.; Xue, Q.; Wang, Z.; Liu, Z.; Tang, Z.; Wang, Y.; Kang, F.; Li, B.; Zhi, C. An Extremely Safe and Wearable Solid-State Zinc Ion Battery Based on a Hierarchical Structured Polymer Electrolyte. Energy Environ. Sci. 2018, 11 (4), 941-951. https://doi.org/10.1039/c7ee03232c.

(38) Zhang, S.; Yu, N.; Zeng, S.; Zhou, S.; Chen, M.; Di, J.; Li, Q. An Adaptive and Stable Bio-Electrolyte for Rechargeable Zn-Ion Batteries. J. Mater. Chem. A 2018, 6 (26), 12237 12243. https://doi.org/10.1039/c8ta04298e.

(39) Huang, Y.; Liu, J.; Zhang, J.; Jin, S.; Jiang, Y.; Zhang, S.; Li, Z.; Zhi, C.; Du, G.; Zhou, H. Flexible Quasi-Solid-State Zinc Ion Batteries Enabled by Highly Conductive Carrageenan Bio-Polymer Electrolyte. RSC Adv. 2019, 9 (29), 16313-16319. https://doi.org/10.1039/c9ra01120j.

(40) Liu, Z.; Huang, Y.; Huang, Y.; Yang, Q.; Li, X.; Huang, Z.; Zhi, C. Voltage Issue of Aqueous Rechargeable Metal-Ion Batteries. Chemical Society Reviews. Royal Society of Chemistry 2020, pp 180-232. https://doi.org/10.1039/c9cs00131j.

(41) Zhang, C.; Holoubek, J.; Wu, X.; Daniyar, A.; Zhu, L.; Chen, C.; Leonard, D. P.; Rodríguez-Pérez, I. A.; Jiang, J. X.; Fang, C.; Ji, X. A ZnCl2 Water-in-Salt Electrolyte for a Reversible Zn Metal Anode. Chem. Commun. 2018, 54 (100), 1409714099. https://doi.org/10.1039/c8cc07730d.

(42) Wang, F.; Borodin, O.; Gao, T.; Fan, X.; Sun, W.; Han, F.; Faraone, A.; Dura, J. A.; Xu, K.; Wang, C. Highly Reversible
Zinc Metal Anode for Aqueous Batteries. Nat. Mater. 2018, 17 (6), 543-549. https://doi.org/10.1038/s41563-018-0063-z.

(43) Zhang, T.; Tang, Y.; Guo, S.; Cao, X.; Pan, A.; Fang, G.; Zhou, J.; Liang, S. Fundamentals and Perspectives in Developing Zinc-Ion Battery Electrolytes: A Comprehensive Review. Energy Environ. Sci. 2020. https://doi.org/10.1039/d0ee02620d.

(44) Huang, J.; Zhou, J.; Liang, S. Guest Pre-Intercalation Strategy to Boost the Electrochemical Performance of Aqueous Zinc-Ion Battery Cathodes. Acta Phys. Chim. Sin. 2020, 0 (0), 2005020-0. https://doi.org/10.3866/PKU.WHXB202005020.

(45) Wang, P.; Shi, X.; Wu, Z.; Guo, S.; Zhou, J.; Liang, S. Layered Hydrated Vanadium Oxide as Highly Reversible Intercalation Cathode for Aqueous Zn-ion Batteries. Carbon Energy 2020, 2 (2), 294-301. https://doi.org/10.1002/cey2.39.

(46) Guo, S.; Qin, L.; Zhang, T.; Zhou, M.; Zhou, J.; Fang, G.; Liang, S. Fundamentals and Perspectives of Electrolyte Additives for Aqueous Zinc-Ion Batteries. Energy Storage Mater. 2021, 34 (October 2020), 545-562. https://doi.org/10.1016/j.ensm.2020.10.019.

(47) Zhang, T.; Tang, Y.; Fang, G.; Zhang, C.; Zhang, H.; Guo, X.; Cao, X.; Zhou, J.; Pan, A.; Liang, S. Electrochemical Activation of Manganese-Based Cathode in Aqueous Zinc-Ion Electrolyte. Adv. Funct. Mater. 2020, 30 (30). https://doi.org/10.1002/adfm.202002711.

(48) Kundu, D.; Hosseini Vajargah, S.; Wan, L.; Adams, B.; Prendergast, D.; Nazar, L. F. Aqueous: Vs. Nonaqueous ZnIon Batteries: Consequences of the Desolvation Penalty at the Interface. Energy Environ. Sci. 2018, 11 (4), 881-892. https://doi.org/10.1039/c8ee00378e.

(49) Tang, Y.; Liu, C.; Zhu, H.; Xie, X.; Gao, J.; Deng, C.; Han, M.; Liang, S.; Zhou, J. Ion-Confinement Effect Enabled by Gel Electrolyte for Highly Reversible Dendrite-Free Zinc Metal Anode. Energy Storage Mater. 2020, 27 (November 2019), 109-116. https://doi.org/10.1016/j.ensm.2020.01.023.

(50) Idota, Y.; Kogure, Y.; Kato, T.; Yano, K.; Arakawa, H.; Miyajima, C.; Kasahara, F.; Ogihara, T. Relationship between Physical Parameters of Various Metal Ions and Binding Affinity for Alginate. Biol. Pharm. Bull. 2016, 39 (11), 1893-1896. https://doi.org/10.1248/bpb.b16-00127.

(51) Feng, Y.; Zhang, Q.; Liu, S.; Liu, J.; Tao, Z.; Chen, J. A Novel Aqueous Sodium-Manganese Battery System for Energy Storage. J. Mater. Chem. A 2019, 7 (14), 8122-8128. https://doi.org/10.1039/c9ta00474b.

(52) Wang, D.; Wang, L.; Liang, G.; Li, H.; Liu, Z.; Tang, Z.; Liang, J.; Zhi, C. A Superior $\delta$-MnO 2 Cathode and a SelfHealing Zn- $\delta$-MnO 2 Battery. ACS Nano 2019, 13 (9), 1064310652. https://doi.org/10.1021/acsnano.9b04916.

(53) Sun, J. Y.; Zhao, X.; Illeperuma, W. R. K.; Chaudhuri, O.; Oh, K. H.; Mooney, D. J.; Vlassak, J. J.; Suo, Z. Highly Stretchable and Tough Hydrogels. Nature 2012, 489 (7414), 133-136. https://doi.org/10.1038/nature11409.

(54) Qian, H.; Greenhalgh, E. S.; Shaffer, M. S. P.; Bismarck, A. Carbon Nanotube-Based Hierarchical Composites: A Review. J. Mater. Chem. 2010, 20 (23), 4751-4762. https://doi.org/10.1039/c000041h.

(55) Bender, D.; Schuster, J.; Heider, D. Flow Rate Control during Vacuum-Assisted Resin Transfer Molding (VARTM) Processing. Compos. Sci. Technol. 2006, 66 (13), 2265-2271. https://doi.org/10.1016/j.compscitech.2005.12.008. 
Table Of Content
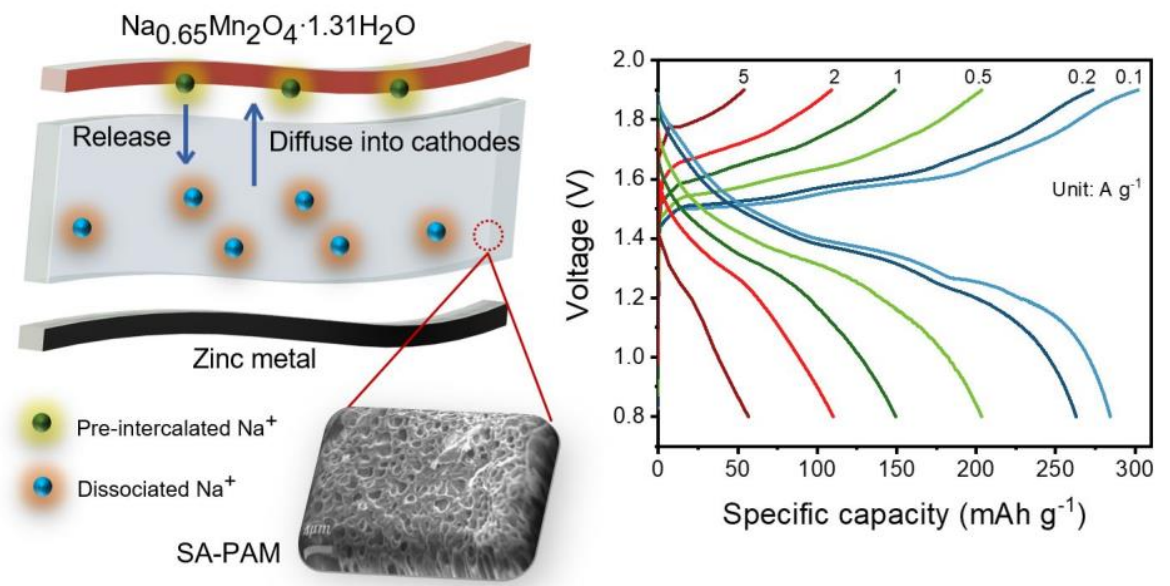